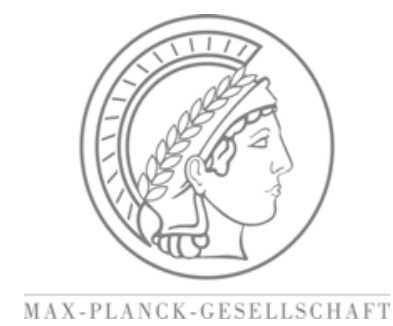

\# 0903

Is Novelty always a good thing? Towards an Evolutionary Welfare Economics

by

Christian Schubert

The Papers on Economics and Evolution are edited by the Evolutionary Economics Group, MPI Jena. For editorial correspondence, please contact: evopapers@econ.mpg.de

ISSN 1430-4716

(C) by the author

Max Planck Institute of Economics Evolutionary Economics Group Kahlaische Str. 10

07745 Jena, Germany

Fax: $++49-3641-686868$ 


\title{
Is Novelty always a good thing? Towards an Evolutionary Welfare Economics*
}

\author{
Christian Schubert \\ Max Planck Institute for Economics \\ Kahlaische Str. 10, 07745 Jena \\ schubert@econ.mpg.de
}

\begin{abstract}
Schumpeter's and Hayek's view of market coordination as being not about efficiency, but about endogenous change and never-ending discovery has been increasingly recognized even by the mainstream of economics. Underlying this view is the notion of creative learning agents who bring about novelty. We argue that apart from the challenges it poses for positive theorizing, novelty (be it technological, institutional or commercial) also has a complex normative dimension that standard welfare economics is unsuited to deal with. We show that welfare economics has to be reconstructed on the basis of evolutionary-naturalistic insights into the way human agents bring about, value and respond to novelty-induced change.
\end{abstract}

Keywords: Novelty, Endogenous Change, Preference Formation, Welfare, Justice.

JEL: D63, O12

* I wish to thank Martin Binder, Wilfred Dolfsma and Marco Guerzoni for helpful comments on an earlier draft. Any remaining errors are mine, of course. 


\section{Introduction}

What's the point of letting the market coordinate economic activities? This question can be answered in two radically different ways. While the neoclassical mainstream of economics points towards the market's capacity to yield maximum allocative efficiency, heterodox economists rather focus on Schumpeterian and Hayekian ideas about the market's role in fostering change and innovation and in processing valuable knowledge. The underlying conceptions of "welfare" diverge just as much as the corresponding positive visions of the economy. In an evolutionary perspective, capitalism should be understood and appreciated as a restless "engine of growth" (Nelson 1990) rather than as a mechanism to generate stable equilibria by having rational agents economize on scarce resources.

It may be argued that the evolutionary view of the market and its merits is able to reflect the reality of modern capitalism and its awe-inspiring capacity to revolutionize our way of life much better than the textbook models of mainstream, neoclassical economics. The processes underlying the generation and diffusion of commercial, technological or institutional novelty have been and continue to be successfully explored using modeling techniques inspired by the evolutionary approach (for surveys, see Nelson 1995; Witt 2008). There is, however, still a major asymmetry between the evolutionary and the neoclassical view, in that only the latter is presently able to consistently evaluate what the market brings about. Lacking any independent elaborate notion of "welfare", evolutionary approaches remain silent in this regard. As a consequence, any scientifically informed critical discussion about goals and criteria of policy-making has to be left either to the policy-makers themselves or to the neoclassical economists. At the same time, the latters' normative ideas and ideals (such as, most prominently, the notions of Pareto efficiency and "market failure") are intuitively rejected by most evolutionary scholars interested in these matters, mainly due to the fact that they are tailored to the conditions of a static perfect-information world (Metcalfe 2001; Hodgson 1999). ${ }^{1}$

Hence, evolutionary economists are stuck in a dilemma: They may rightly claim to better positively understand what's going on in the market economy, and they may even rightly sense to have a better intuition about when things go wrong there, but as yet

\footnotetext{
${ }^{1}$ see also Hayek (1948: 92-106) for an early forceful critique.
} 
they do not have the (conceptual and theoretical) tools to back this intuition, i.e., to generate independent, well-justified policy advice.

One may object that there is, within the Evolutionary Economics field, a large literature concerned with practical advice related to, e.g., innovation or entrepreneurship policy, and this is certainly true. ${ }^{2}$ A closer look reveals, though, that this literature is mostly concerned with what John Neville Keynes (John Maynard's father), in his "Scope and Method of Political Economy" (Keynes 1917), dubbed the "art of political economy", namely, the branch of instrumental economics which starts from some given policy goal and examines the most effective tools and means to realize it. In this respect, instrumental Evolutionary Economics tends to start from the (often implicit and rather broad) presumptions, (i) that policy is in fact able to influence intensity and direction of innovative activities, and (ii) that, given this capacity, it should foster novelty, learning, variety and innovation-induced growth in an economy. What is lacking, then, is an examination of questions such as

- Is it necessarily a good thing to (unconditionally) foster innovation?

- Is structural change desirable per se - the more so, the faster it proceeds?

- How should novelty-induced costs and benefits be weighed?

- How can we define and measure "social welfare" in an evolutionary setting (where, e.g., individual preferences evolve as well)?

So far, hardly anything has been done to move beyond the purely instrumental analysis of policy-making. This has two key consequences. On the one hand, policy statements by evolutionary economists tend to remain somewhat incomplete and superficial. On the other hand, scholars who dismiss orthodox criteria such as Pareto or Kaldor-Hicks efficiency on the grounds of, e.g., their static nature cannot easily support their critique by referring to some alternative set of criteria that are superior in some important respect, such as being consistently applicable to social phenomena in an evolving economy. This second issue relates to the potential which an evolutionary theory of welfare could have for enriching welfare economics itself. Given the increasingly abstract character and narrow informational basis of the latter, its own practical relevance has been questioned from very different angles (Sen 1977; Sen 1996; Atkinson 2001; Ng 2003; Scanlon

\footnotetext{
2 see, e.g., Metcalfe (2005), Audretsch et al. (2007).
} 
1991). Some of these angles look familiar to evolutionary economists: For instance, the problem of how to deal with preference change while sticking to a preference-based notion of welfare is increasingly discussed (Weizsäcker 2005; Sugden 2004). ${ }^{3}$ Consequently, welfare economics' main theorems and results are not only questioned by most evolutionary economists due to their static nature, but they prove to be more or less irrelevant in the context of many practical normative issues which turn out to be most interesting for contemporary economists in general: Examples include questions about how to evaluate government interference in processes of social norm or preference formation, based on the purposeful manipulation of framing effects ("Libertarian Paternalism") or the regulation of "social meaning" (Sunstein and Thaler 2003a, 2003b; Lessig 1995).

Thus, we argue that Evolutionary Economics should finally start investigating the normative implications of its positive insights, by elaborating upon an evolutionary welfare economics (henceforth EWE). Intuitively, an evolutionary perspective should not only make a difference in terms of how to do positive research in economics, but also in terms of welfare-related issues. As Richard Nelson and Sidney Winter already pointed out in their "Evolutionary Theory of Economic Change" $(1982)^{4}$, "it is apparent that an evolutionary view of what is going on in the world of firms and industries strongly influences how one looks at the question of what should be going on", leading them to conclude that such a view would require a "rethinking of normative economics" (ibid.: 356). Put differently, in light of what they know about economic behavior and social phenomena, evolutionary economists should develop their own ideas about what goals and criteria ought to guide economic policy-making, how these could be justified, weighed against each other, and operationalized. Moreover, the way these issues are analyzed should be based on background assumptions that are compatible with those guiding positive research in Evolutionary Economics.

The present paper aims at suggesting a way to construct an EWE. A conceptual framework is presented that clarifies in which sense positive insights from Evolutionary Economics may play a role in generating welfare judgments and developing policy advice. The argument is built around two key hypotheses. The first one is

\footnotetext{
${ }^{3}$ classical treatments include v.Weizsäcker (1971) and Elster (1982).

${ }^{4}$ italics in the original.
} 
methodological: We argue that evolutionary economics does have the conceptual and theoretical resources to develop an EWE which could then guide, within a framework inspired by Constitutional Economics thinking, the critical reflection and exploration of the complex normative dimension of innovation. More precisely, these resources can be located in the naturalistic underpinnings of the model of human behavior that is used in the field (Witt 1991; Binder 2008). This model has important implications for our understanding of what determines human welfare. Thus, the behavioral foundations of such a theory of welfare will be much more empirically informed than is the case in the orthodox approach. The second hypothesis is of a normative nature: We show that normative reasoning on the basis of an evolutionary conception of the economy leads to two conflicting views on the nature of welfare: Welfare can either consist directly in what individuals value or desire (Vanberg 1994; Kerstenetzky 2007) or it can consist in the smooth working of the economic system itself, seen from a supra-individual perspective. In our case, this smooth working would amount to the capacity of the evolving economy to process dispersed knowledge, bring about variety, facilitate learning and foster change ${ }^{5}$. Since the individualistic and the systemic view are hard to reconcile, much of the justificatory ground-work within an EWE will presumably concern striking a balance between them.

The paper proceeds as follows. Section 2 briefly reviews the key ideas that can be found in the literature on the normative implications of Evolutionary Economics. Based on a significant gap we will identify there, section 3 lays the conceptual groundwork for an evolutionary approach to welfare. Section 4 focuses on the implications of the phenomenon of preference change as the key issue that distinguishes the evolutionary approach to welfare from Paretian accounts. Section 5 briefly discusses some possible applications and discusses the problem of the conflicting individualistic and systemic interpretations of welfare, and section 6 concludes.

\footnotetext{
5 this seems to be Potts' (2004) background assumption. See also section 5, below.
} 


\section{The evolutionary viewpoint}

When evolutionary economists reason about the political and in particular the normative implications of their research agenda, there are two issues finding almost general agreement. First, most scholars in the field concur in that the key concepts of orthodox welfare economics cannot be used to evaluate phenomena that emerge in an evolving economy. Second, there is widespread agreement that any reasoning about policy or welfare implications has to come to terms with the problem of genuine uncertainty that characterizes any complex, endogenously evolving economy. Let's have a closer look at these two issues.

Mainstream economics is, to paraphrase Robbins (1935: 16), about how rational agents economize on a given set of scarce resources. When put this way, the economic problem has a straightforward normative solution: optimality is reached as soon as the economizing has been done in extremis, with all resources being allocated in an efficient and stable equilibrium. According to the first theorem of Welfare Economics, this state of minimal waste is realized under conditions of friction-less perfect competition. The positive and the normative perspective are closely linked, for the Robbinsian approach to frame the problem of economic life has a latently normative flavor (Witt 2004): Economizing on scarce resources is seen as inherently desirable. Hence, the conceptualization of the kind of issues economics should deal with already presupposes a quite narrow set of possible welfare criteria, viz., the criteria of Paretian efficiency.

What about the evolutionary way to frame the economic problem? The literature focusing on the conceptual basis of Evolutionary Economics (Nelson 1995; Witt 2008) rejects the Robbinsian conception in favor of a more complex view: Economics is understood as being about the way heterogeneous, boundedly rational and creatively learning agents bring about novelty and change at all levels of economic life. For logical reasons, novelty-induced change tends to be surprising and unsettling. Stable equilibria, should they ever appear, seem to be uninteresting, both in a positive and in a normative sense. As Hayek (1945: 523) put it, "economic problems arise always and only in consequence of change". 6 Individuals experiment and learn in a time-consuming (and necessarily "wasteful") process which involves their acquiring new preferences, and

${ }^{6}$ See also Hayek (1948: 101): "[A]11 economic problems are created by unforeseen changes which require adaptation“. 
which leads to the creation of interaction- and coordination-based order rather than equilibrium. Order should be understood in a procedural rather than in a static sense.

Clearly, there is no place for an argument analogous to the mainstream in extremis reasoning here, for there is no "naturally" evolving order per se. Rather, the order's properties depend crucially on the nature of its institutional framework. Given such a framework, the resulting order can have desirable and undesirable characteristics - this has to be found out on the basis of some independently construed welfare criterion (Vanberg 1994; Buchanan 1977). Thus, this way to frame the economic problem avoids at least the stark normative connotations of the Robbinsian approach. At this conceptual level, the one thing that can be said is that normative issues potentially arise whenever change happens. There is no perfectly stable and perfectly desirable state of optimality that could conceivably ever be reached. Rather, adopting an evolutionary view leads to the suggestion to focus on the question which institutional arrangements are suited to deal with change-induced societal problems, with the standard underlying the meaning of "better" to be defined in an independent way.

Hence, from an evolutionary perspective on the economy the actual definition of social welfare does not have to be prespecified in a narrow way. The only thing that seems to be excluded at this point is the identification of social welfare with static Paretian efficiency. On the other hand, given its well-developed repository of empirically backed insights into the determinants of economic behavior and the working properties of institutions, Evolutionary Economics allows to derive a rich set of "policy implications" on the instrumental level. These tend to have a specifically evolutionary flavor. For given any pre-assumed policy goal, possible and effective ways to reach that goal depend strongly on whether a neoclassical or an evolutionary model of the economy (with its specific epistemic conditions) is assumed to apply in the background.

Thus, it is hardly surprising that most evolutionary economists, when examining policy- and welfare-related issues, have remained almost exclusively on the instrumental level. There, one aspect has caught most attention: In a complex, evolving market

\footnotetext{
${ }^{7}$ We assume that this is what Nelson and Winter (1982: 357) have in mind when speculating that "a normative theory consistent with an evolutionary approach to positive theory almost certainly will be complex and messy. It is unlikely that one will be able to prove many sweeping normative theorems of the sort that are now contained in our advanced treatises and elementary texts. This, however, should not cause despair."
} 
environment, most policy measures generate indirect or long-term side effects (Pelikan 2002). These side effects are sometimes perverse, often surprising, and always hard to track. This is due to the fact there will virtually always be agents who are negatively affected by a given policy measure. Reacting to policy-induced losses in terms of their wealth or, more generally, their subjective utility, these agents will try to find creative and, hence, unpredictable - ways to at least partially circumvent these effects (Wegner 1997). The history of economics certainly provides ample evidence for such a dynamic interplay between policy-makers' moves and economic agents' countermoves.

Given this problem of "creative responses" and the ensuing harsh epistemic conditions of policy-making on the one hand, and on the other hand the indeterminacy with respect to the conceptualization the "common good" that should guide policymaking, most scholars in applied Evolutionary Economics have reacted in one of the following two ways.

- The first option is to leave the precise meaning of "welfare" somewhat open (open, that is, beyond the usual rejection of orthodox conceptions). It may then be defined in a pragmatic or eclectic way as including usual goals such as "growth", “economic development" or "output". Dolfsma (2005) would be an example of this approach. Schumpeter himself may also be classified here ${ }^{8}$, as well as many scholars engaged in applied Evolutionary Economics who resort to "historical standards". Foss (2006) aptly describes this strategy: "Identify a historical success story (Finland in the 1990s?), and let the qualities that characterize this success story become the relevant standard."

- The second option would be to look out for a dynamic welfare criterion. On the most basic level, this then amounts to equating social welfare with "innovation" or "learning": Policy should aim at establishing conditions that encourage innovative behavior and foster learning on all levels of the economy (Hodgson 1999: ch. 11). In the words of Metcalfe (2001: 561f.), the economic process should be evaluated according to how far it succeeds in "overcoming ignorance". This, he argues, is a standard that would be more "exacting" than the conventional

\footnotetext{
${ }^{8}$ see his suggestion in "Capitalism, Socialism and Democracy" that "we shall call that system relatively more efficient which we see reason to expect would in the long run produce the larger stream of consumers' goods per equal unit of time" (Schumpeter 1942: 190, italics omitted) and the fact that here and in related work he never really elaborates upon this notion of efficiency or welfare.
} 
criteria of welfare economics. Views like these seem to reflect an older idea developed by Douglass North (1990) in the context of his normative analysis of institutional arrangements: In a dynamic economy, he argues, social states should be judged according to their "adaptive efficiency", a criterion which he defines, somewhat vaguely, as being "concerned with the willingness of a society to acquire knowledge and learning, to induce innovation, to undertake risk and creative activity of all sorts, as well as to resolve problems and bottlenecks of the society through time" (ibid.: 80). Although the concept has been much cited ever since, it has never really been systematically elaborated upon as an element of an evolutionary approach to normative economic theorizing.

Thus, it seems that evolutionary economists, when moving beyond the purely instrumental level of analysis and beyond mere normative eclecticism, tend to equate "welfare" with "innovation". This, however, means that they effectively fall back to a kind of reasoning that we have already identified as being characteristic for the mainstream approach to social welfare: Assume that economic life is about $\mathrm{X}$ ("economizing on scarce resources", say), then it is desirable to have more rather than less of $X$, and then policy should aim at fostering $X$, until an optimum state of "perfect X" will eventually be reached. Quite analogously, one might argue, that when economic life is instead actually about Y ("learning and change"), then policy should aim at fostering $\mathrm{Y}$ as much as possible. But can an optimum of "perfect $\mathrm{Y}$ " conceivably be reached? This seems to be implausible, for two reasons: First, while in the mainstream view, "economizing on scarce resources" has an in-built "optimum" limit, due of course to the assumptions of given resources and given preferences, in the evolutionary perspective "learning and change" does not have such a limit: Learning goes on infinitely, without ever reaching an end. Second, there is no "natural" learning-induced order without any institutional framework. Hence, any normative judgment about the order has to depend on and refer to the framework, i.e., to something external to the order itself.

Having established the need for some external benchmark, it may be questioned whether most people would really prefer to live in a world where welfare is equated with "learning and change" and nothing else. To this question we turn now. 


\section{A problem of justice}

Does it make sense to conceptualize welfare as being about "innovation" or "learning" or "change" tout court? While shying away from any systematic elaboration of the normative dimension of the "gales of creative destruction", Joseph Schumpeter (1912) ${ }^{9}$ proved to have at least a clear intuitive grasp of the complexities involved by processes of innovation-induced growth:

"[A] process of degeneration, of degradation of large circles (of society) accompanies the upward movement... Large circles see their economic basis being pulled away. This does not happen abruptly, but gradually. Through generations, the people affected live a deprived existence full of hopelessness. Their moral and intellectual powers dwindle, the more so the more the economic atmosphere they find themselves in is darkening.

An observer from outer space wouldn't notice these phenomena, so fascinating is the development at large - and those losses are just their reverse. They are due to the fact that the services these agents offered are now being offered in a better way. Even the suffering thus caused serves to get rid of the obsolete and to impel novelty. Those who are playing the drama, however, as well as those observers close to them, think differently about it. They cannot ignore the shouting of the crunched who are crushed down by the wheels of novelty."

Evolutionary change systematically involves winners and losers (Witt 1996). Winners may outweigh losers, losses may be "short-term", costs and benefits may accrue to the same or to different people over time - everything is possible. But an evolutionary theory of welfare would have to give a well-justified answer to the question how gains and losses should be weighed, whether losers should be compensated, and whether gains through innovation are worth pursuing.

First of all, we have to examine the ambivalent nature of evolutionary economic change in more detail. A closer look at the underlying process of social learning reveals that equating welfare and innovation misses something that is not only essential as a positive explanandum, but also in terms of its normative relevance. As Metcalfe (2001: 24) puts it, "progress in knowledge is necessarily non-uniform". ${ }^{10}$ For economically relevant knowledge is always prone to be falsified and become obsolete when circumstances change. In an economy that operates outside a state of equilibrium, there are at all times "internally generated reasons for beliefs to change" (ibid.). With the epistemic basis of economic behavior in permanent turmoil, though, it follows that

\footnotetext{
${ }^{9}$ my translation from the German original.

10 italics added.
} 
economic change itself necessarily proceeds in an uneven way: As Metcalfe (2001: 565f.) puts it, "advance in some directions is associated with deterioration in others", even inevitably so: „Creative destruction implies the destruction of some activities as a necessary element in the growth of others“" (ibid.).

Apart from its unquestionable beneficial impact on human welfare (however broadly defined), human innovativeness typically also involves risks and potentially severe detrimental consequences (Witt 1996; Witt 2003) ${ }^{11}$. New products, services, institutional arrangements or organizational schemes may make alternative "problem solutions" and their underlying knowledge obsolete. The costs incurred may be reflected in changes in the relative price vector ("pecuniary externalities") or not ("technological externalities"). These detrimental consequences are directly linked to the way knowledge itself develops: society's knowledge base may develop in such a way that, for instance, large stocks of "human capital" lose their market value; the diffusion of productive knowledge on how to cope with detrimental spillovers may be hampered; knowledge on ways to organize markets may develop, although people do not value it positively. ${ }^{12}$

This problem of valuation points toward an important distinction between two kinds of knowledge that may or may not develop harmoniously. Put in general terms, positive or instrumental knowledge may develop in one direction while "normative knowledge" (i.e., people's knowledge about their own personal preferences, values and goals) may develop in a quite different direction. Consequently, society's knowledge base, i.e. its repository of problem solutions, would then no longer correspond to the actual "demand" for problem solutions.

Given the uneven nature of economic evolution, it appears now that what is missing in the Evolutionary Economics literature on normative issues is the recognition that when observing and studying processes of "creative destruction", we are facing a problem of justice. We cannot do without a concept of justice when questions about how to deal with trade-offs between novelty-induced gains and losses have to be solved. This holds independently of whether gains and losses accrue within one period or are spread over several time periods: Typically, novelty-induced destruction is imminent, while

\footnotetext{
${ }^{11}$ cf. Buchanan's (1977: 27-30) hint at the possibility of "spontaneous disorder".

12 Controversial market products such as genetically modified food or „markets“ for human organs may serve to illustrate this, as may, on the other hand, the market's capacity to provide "green products" in a way that can be argued to increase social welfare, broadly understood (see section 4, below).
} 
gains are realized in subsequent periods. Note the generality of the notion of justice that is required here: Within the large set of conceivable answers to the trade-off question, the typical quasi-utilitarian welfare economics position with its purely quantitative calculus in terms of novelty-induced benefits and novelty-induced costs qualifies as one option only. $^{13}$

Hence, "justice" should be understood in the most encompassing way. At the most abstract level, any concept of justice comprises (i) a notion of welfare as the "currency" which is used in the justice calculus, and (ii) a rule about how to weigh the different welfare entries on both sides of the balance sheet. Applying a criterion of justice involves the assessment of relative well-being among individuals affected by a certain social state, social process or policy intervention.

As a normative concept, "justice" comprises both procedural as well as distributive criteria, i.e. criteria pertaining both to the (non-arbitrary) way rights and duties are allocated and procedures enforced as well as criteria concerning the distributive patterns brought about by market forces and policy interventions. Concerning the distributive dimension, we know as an empirical fact that novelty-induced change benefits the average individual. But if this means that it makes some agents win and others lose today, or if it makes some lose today and some or even (nearly) all win tomorrow (where "tomorrow" may mean "a few decades from now"), it is evident that some difficult trade-offs have to be solved when balancing these effects, that any solution found needs to be justified somehow, and that any justification needs to be based on some normative theory of justice, necessarily involving a theory of human welfare.

Hence, moving beyond the pure instrumental level of analysis leads us to the desideratum of a concept of justice that should tell us under which conditions the phenomena accompanying evolutionary economic development can be seen as "just" and legitimate. It may be legitimate to encourage learning and foster innovation that generates serious hardship for a subset of the affected population, but it is not necessarily so. Rather, this evaluation depends on a normative analysis involving a justice "calculus" that in turn critically hinges on a conception of welfare (as the "currency" of justice).

\footnotetext{
${ }^{13}$ A Rawlsian approach (,,inequality of winners and losers is just as long as losers are better off in the regime allowing the inequality than in a regime disallowing it") would be an alternative candidate, see Rawls (1971: ch. 2).
} 
To be sure, this concept of justice and its related criteria have to be used within the context of an endogenously evolving economy with its harsh epistemic conditions. This is difficult, but not outright impossible. Adopting the contractarian toolbox of Constitutional Economics (Buchanan 1977; Vanberg 1994; Vanberg 2006), we will argue that a concept of justice that serves our purposes can in fact be construed under the three following conditions. First, given the genuine uncertainty prevailing in an evolving economy, it should be tailored to the normative analysis of (constitutional) rules that generate observable patterns of outcomes rather than specific allocative and distributive states. Any normative perspective that starts from an evolutionary world-view has to be process-oriented in the sense that "rather than seeking to control outcomes directly, it seeks to affect outcomes indirectly, by subjecting the processes from which outcomes emerge to general rules that promise to generate overall desirable patterns of outcomes" (Vanberg 2006: 204).

Second, the concept of justice should be embedded in an overarching principle and criterion of "general consensus", stating that those rules are "just" that are generally agreed upon by the individuals affected by them. "Consensus" would replace "social welfare maximization" here, because the latter presupposes a specific and probably implausible solution of the trade-off between gains and losses: In the process of maximizing something, (positive) gains and (negative) losses would simply be seen as quantitative variables to be added up and offset interpersonally. In order to avoid such a narrow pre-specification, we suggest to resort to general consensus as a more general benchmark of legitimacy. Among all conceivable normative criteria, this is the one requiring the weakest prior value judgments: It is derived from the basic principle of Normative Individualism, according to which it is only actual current real-world preferences (and consent) that carry genuine legitimizing force (Vanberg 2006). Thus, "just" will be understood in the light of a general consensus criterion in the following, meaning that some balance of gains and losses is just insofar as it can plausibly (with good reasons) be taken to be generally acceptable.

Third and most importantly, under the conditions of an evolving economy with evolving preferences, such a consensus criterion cannot be made operational without at least a minimum specification of the processes driving the formation of individual preferences (which constitute the consensus or the "social contract"). It is at this point 
where the evolutionary theory of human welfare steps in. This issue will be examined in more detail in the following.

\section{How to track a moving consensus}

Concluding what has been said so far, we can state that the results and side effects of endogenous economic change can be classified as "legitimate" insofar as they emerge under rules that in turn can plausibly be judged acceptable by all individuals affected. This means that they can be seen as conforming to the individuals' common "constitutional interests". This way to conceptualize the normative problem of Evolutionary Economics implies that we cannot stipulate a priori that the detrimental effects of "creative destruction" are somehow automatically or naturally compensated by the beneficial impact of economic novelty and learning. Rather, we have to examine in detail what kinds of losses and gains are involved and how they relate to the welfare of the individuals affected by them, in order to be able to make any meaningful statement about whether the resulting balance can be qualified as "just" in the sense it is understood here. Two questions have to be examined here: First, it has to be specified what is meant by "losses and gains", i.e., which "welfare currency" or "currencies" should be used to express these variables. This is a normative task. Second, given the answer to the first question, the value of the variables has to be examined empirically. This is a task that goes beyond the scope of the present paper.

Note that the criterion of legitimacy suggested above has to be made operational under the difficult epistemological circumstances of an evolving economy. The key implication of this concerns the status of individual preferences and the corresponding difficulty in conceptualizing welfare (the yet-to-be-specified "currency" of our justice criterion). While preferences can conveniently be assumed to be fixed and "given" in the context of a static resource allocation game, we have to drop that assumption in the case of an economy that generates novelty from within. When confronted with a never-ending stream of new ideas, goods and services, individuals adapt their preferences and acquire new ones. To illustrate, imagine consumer Cecilia. In the light of newly emerging positive-instrumental knowledge about the characteristics of a new good (say, the capacity of a new kind of eco-friendly car to satisfy her preference for saving the 
environment), Cecilia may acquire a new preference for this car which did not exist before. Hence, new positive-instrumental knowledge shapes the development of her normative (preference-related) knowledge. Imagine further that the introduction of the new car is due to incentives shaped by a new policy measure initiated by the government. Thus, a policy intervention would have influenced the development of Cecilia's individual preferences, making the latter endogenous to the economic system. As a consequence, her preferences and the degree of their satisfaction no longer qualify as an independent external measuring rod for policy interventions - neglecting this implication would lead us into logical circularity problems. ${ }^{14}$ It seems that the notion of welfare has to be redefined.

From a traditional Constitutional Economics perspective, one may object at this point that while the satisfaction of a set of preferences that is "given" at any point in time does indeed no longer qualify as an adequate standard of welfare, this does not rule out a procedural criterion of preference development. Thus, the maximization of opportunities to form and satisfy any preference whatsoever may still be a plausible criterion and may in fact be the only one acceptable from an individualistic perspective. Put differently, while the manifold preferences individuals hold in a pluralistic society are irreducibly heterogeneous, at least everyone will agree that everyone would benefit from a constitutional regime that maximizes each agent's set of opportunities to satisfy one's preferences (Sugden 2008). This would then leave a constitutional system granting maximum individual freedom as the only legitimate outcome.

This view, though, does not stand empirical scrutiny. The development and satisfaction of any actual preferences, however contingent they may be, is not the only thing real-world individuals care about and value (Wegner 2008). According to all available empirical evidence on the content of policy-related preferences of real-world individuals, the liberal views of standard Constitutional Economics on the substance of the social contract are prima facie only shared by a minority of citizens ${ }^{15}$. According to basic principles of Normative Individualism the citizens are however also the exclusive principals of policy-making. Whatever they agree to is legitimate. Hence, there is an apparent gap between the substantive claims of Constitutional Economics and the

\footnotetext{
${ }^{14}$ Penz (1986: ch. 6) is the locus classicus for this problem.

${ }^{15}$ see, for example, Vis and van Kersbergen (2007) and Boeri et al. (2001). See from a theoretical Constitutional Economics perspective Buchanan (2005).
} 
requirements of Normative Individualism proper. It calls for abandoning the standard approach to conceptualize welfare and consensus on the basis of the satisfaction of preferences alone.

Hence, we face the need to redefine welfare. This can be done in at least four different ways. Welfare may be conceptualized as being about happiness or subjective well-being or "experienced utility" (Ng 2003; Kahneman et al. 1997). Apart from this and totally independent of any hedonic considerations, it may also be conceptualized as being about the satisfaction of underlying genetically determined or culturally learned wants (which serve as "inputs" into the process of preference formation, Witt 2001) ${ }^{16}$, about objectively measurable capabilities humans are supposed to strive for universally (Sen 1996), or about partly measurable opportunities to learn and express one's preferences, irrespective of their contingent nature (Sugden 2004; Sugden 2007). In any of these cases, preferences lose their traditional status as the exclusive measuring rod of welfare. Put differently, they now no longer play their traditional exclusive role as goals, but rather acquire an instrumental status: Preferences are to be seen as tools to, e.g., increase happiness. As such, they will be more or less effective ${ }^{17}$ and can be made the subject of critical reflection and deliberation. At the same time, the focus of normative analysis moves one step "beyond" preferences, i.e., toward the factors determining their formation and scope. Notice that these happen to be the factors that Evolutionary Economics, with its empirically informed ("naturalistic") model of human behavior, is well-equipped to deal with (Witt 1991).

While we will not go into a detailed discussion of the four approaches suggested in the literature, notice that what is essential in the context of the present discussion is the fact that in the context of an evolving economy with evolving preferences, it seems to be problematic to stick to a uniform notion of welfare. Rather, in an evolutionary welfare economics perspective, things get multi-faceted and quite intricate: Welfare consists of several components which are not necessarily reducible to some underlying onedimensional "basic currency": While, for instance, happiness may be quantified using

\footnotetext{
${ }^{16}$ These wants differ from preferences in being non-comparative drives to engage in certain activities. Basic wants include the needs for food, water, sleep, warmth, sex, etc., but also psychological needs such as the need for cognitive arousal and the need to comply with social norms. See Witt (1991) and Witt (2001) for details.

${ }^{17}$ see, e.g., Frey and Stutzer (2007) on the human tenedency to mispredict the hedonic impact of consumer decisions.
} 
hedonic measures that track a person's experienced "pleasure", the measurement of opportunities to act and learn proceeds along quite different lines. While of all conceivable components of welfare, four have received some attention in the recent literature on the constituents of a "good life" - namely, subjective well-being, want satisfaction, capability and opportunity - we should not even assume that there are not many more essential components out there in the real world to be discovered.

Hence, in the context of an evolving economy, the basic notion of our concept of consensus-related justice, viz., welfare, loses its precise uniform meaning. In particular, we cannot derive any hypotheses about what kind of rule is generally acceptable by referring to the actual observable preferences of the individuals. Rather, given the variable and contingent nature of individual preferences, we have to focus on the factors determining their formation. This step is quite significant, as it has two important implications.

First and most obviously, it involves a major modification of the welfare economic analysis and a shift of attention towards the "naturalistic" factors underlying the formation of individual preferences. Thus, "consensus" cannot be identified on the basis of whatever the individuals happen to prefer at a given point in time. Rather, it has to be identified in light of what makes them prefer the things they prefer. Insights about the process of preference formation may then even clear the way for deriving basic material statements about universal features of human preferences. ${ }^{18}$ Methodologically, this step involves overcoming the pure subjectivism that characterizes most of traditional Constitutional Economics, where preferences tend to be taken at face value, without any further inquiry into the way they were formed. This subjectivism seems to be inadequate in the context of an evolving economy with evolving preferences. Rather, our analysis suggests to aim at a material specification of the "social contract", given the background assumption that the corresponding consensus is not static, but evolves itself over time. Metaphorically, picturing people's consensus as the sea's surface pattern, when we stop assuming the sea to be unchanging, we will have to know a lot about underwater currents in order not to lose sight of the pattern itself.

The second main implication concerns the methodological status of the results of our normative analysis. Given that the notions of preference, welfare and consensus lose

${ }^{18}$ see Witt $(1991 ; 2001)$. 
some of their precise contours, it gets more difficult to derive statements about what kind of rules (in a comparative institutional analysis) can be seen as legitimate (read: "generally acceptable") and which kinds of rules do not qualify as such. Hence, it would seem to be necessary to "downgrade" the status of the results of the kind of normative analysis that has been sketched above. Statements about the legitimacy of alternative rules can only be of a conjectural nature. After having identified the effects of, say, some constitutional rule on the various determinants of individual preferences and welfare, it is as yet unclear exactly how this translates into an overarching result in terms of "agreement" or "consensus". Thus, we are left with the option to develop hypothetical statements of the following form: "Given what we know about the way individual preferences are formed and welfare is determined, constitutional rule $\mathrm{R}$ should be acceptable to the individuals affected" - or, somewhat more precisely:

"If it is the case that (i) the preferences of the members of society $\mathrm{S}$ are determined by factors $\mathrm{F}$, and if it is the case that (ii) rule $\mathrm{R}$ has effect $\mathrm{E}$ on the economy and, hence, on $\mathrm{F}$, then rule $\mathrm{R}$ should be able to command general agreement by the members of $\mathrm{S}$ ". ${ }^{19}$

Notice that statements of this kind are falsifiable in the following "practical" sense: If the individuals addressed by the scientific observer in this way actually do agree with the statement (by deciding to vote for R, say), then it is not (yet) falsified.

Due to its admittedly weak status, conjectural statements of the kind described above are to be understood as a mere proposition as to the content of a society's "social contract", i.e., as to the set of constitutional rules that we have reason to believe can find unanimous consent among the individuals affected. Let's assume, for the sake of the argument, that there exists a structure of political decision processes that allows individual policy-related preferences to be translated into actual collective choices in an unbiased way. ${ }^{20}$ Then any hypothetical statement about the acceptability of some rule can be falsified by the individuals actually not supporting the corresponding policy measure

\footnotetext{
${ }^{19}$ A statement of this kind differs from simpler hypothetical imperatives (HI) in the following sense: While ordinarily, a HI states the most effective means, given some pre-specified goal, the HI suggested here takes goals as a result of a societal consensus where knowledge on the processes working on the consensus is taken as given. In this sense, one might call this kind of statement an "extended hypothetical imperative". ${ }^{20}$ Put differently, there are no principal-agent problems. This is a heroic assumption, to be sure, but given that principal-agent issues concern the instrumental dimension of policy-making, it is necessary in order to clarify our main normative argument.
} 
unanimously. Hence, conclusions of normative reasoning cannot legitimize anything per se. In the way they are issued by economists, they only play a role as one among many different inputs into the ongoing process of public deliberation about the goals, criteria and concrete steps of policy-making (Witt 1992) ${ }^{21}$

\section{Applying the tools}

How can the abstract toolbox of Constitutional Economics, complemented by "naturalistic" insights into the factors determining processes of preference formation be put to use? The key tool that can be applied here is the thought experiment involving the "veil of ignorance" in the sense of Rawls (1971).

Let's imagine a group of heterogeneous individuals gathering, in their role as democratic principals, behind the veil of ignorance in order to agree on a social contract for an innovative welfare-creating market game. The assumptions about their informational endowment are, of course, crucial. Let them know that the market game itself will be played under conditions of ongoing novelty-induced endogenous change and Hayekian uncertainty. While they do not know their own personal future positions and interests, they do know, however, general facts about what it means to play an innovative market game, including the fact that novelty will necessarily induce benefits as well as costs, that the game cannot be played without incurring temporary imbalances in the social cost-benefit calculus, and the fact that their own preferences will systematically evolve due to learning in the course of the market game.

From an evolutionary perspective, the way this familiar veil-of-ignorance argument is employed will differ significantly from the way it is used in mainstream Constitutional Economics. While the content of the agents' preferences can obviously not be specified in any way that makes agreement outright impossible, an evolutionarynaturalistic outlook allows at least to take a look inside the "black box" of human preferences and preference formation (Cordes and Schubert 2007). It does not make

\footnotetext{
${ }^{21}$ on this, see also Broome (2000: 5): "Democracy has at least two departments. One department is decision making, and here democracy requires that the people's preferences should prevail... Another department... is the forming of people's preferences...Our preferences about complex matters depend on our beliefs, and democracy requires a process of discussion, debate and education, aimed at informing and improving people's beliefs, and moving them nearer the truth... The role of economists in a democracy belongs in the second department, not the first... Economists should aim to influence preferences, not take preferences for granted."
} 
sense, for instance, to assume the agents to be ignorant about the fact that they have and will have (as human beings) a set of genetically hard-wired basic wants that motivates their behavior on a most fundamental level (Witt 2001). Moreover, they know that their own wants and preferences will change in the course of the post-constitutional market game. With respect to a corresponding assumption about their risk preferences, this can already be shown to have significant implications in terms of the policy recommendations of a veil of ignorance-argument (Witt and Schubert 2008). Behind the veil, it may also make sense to endow agents with general theoretical knowledge about the learning mechanisms involved. Insights into the naturalistic determinants of moral (justice-related) norms would be required as well.

How, then, does the knowledge about the fact that their own future preferences will be malleable affect the individuals' deliberation behind the veil of ignorance? Two aspects seem to be particularly striking. First, endowed with basic insights into the naturalistic determinants of their current and future preferences, the individuals can be assumed to perceive and judge them as instrumental rather than as intrinsically valuable. Thus, they will have a genuine interest in having sufficient opportunities to try out new preferences as to their effectiveness in, e.g., allowing the experience to have one's wants satisfied or in delivering hedonic utility. Second, while at the constitutional stage, individuals will evaluate any rule or policy on the basis of their current preferences, the beliefs underlying these preferences will reasonably reflect "educated guesses" (Witt 2003) about how their preferences will be affected by economic processes and policy interventions in the future. Thus, the assessment of indirect and long-term side effects of policy-making - a key token of evolutionary thinking on policy-making (see section 2 , above) - will have to be complemented by hypotheses about the policy's effects on individual preferences. It may, for instance, be asked whether a certain constitutional rule leaves room for policies that constrain the instrumental effectiveness of individual preferences.

In general, deliberating behind the "veil of ignorance" will reflect a much broader notion of welfare than is common in traditional Constitutional Economics. To illustrate, one of the substantive implications that a naturalistically informed veil-of-ignorance argument may have concerns the role of reciprocity in market exchange. As experiments involving the ultimatum game have indicated, individuals appear to be guided by certain 
social norms about the way a mutually realized gain from trade should (at least: not) be divided. Although the laboratory observations reveal a certain degree of heterogeneity, it is evident that people care about the distributive dimension of market exchange acts (Güth and Kliemt 2008). Assume that a naturalistic account of morality would confirm and specify these intuitive insights in the sense that the "revealed" behavioral norms are based on a common disposition. Then one could conclude that real-world individuals understand and perceive market exchange as a reciprocal and, hence, genuinely social relationship (Bruni and Sugden 2008). Then, however, it may be conjectured that they also have a "constitutional interest" in rules that guarantee that gains from exchange are not distributed in a way deemed unfair in light of these underlying distributive norms. ${ }^{22}$ This may hold particularly when the exchange is about novel goods and services whose characteristics are as yet largely unknown to the market participants.

So far, the reconstruction of various aspects in the process of constitutional deliberation has remained within the confines of strictly individualistic principles, with individual principals reasoning about how constitutional regimes may affect their own personal welfare in the future. In an evolving economy, however, this question cannot be answered without considering certain characteristics of the economic system itself. For instance, the impact of a certain constitutional regime on the individual freedom to experiment with new goods and services crucially depends on its impact on the nature of the economic system itself, such as its conduciveness to experimentation, its internal communication cost structure, its ability to create and process decentralized knowledge, or its capacity to adapt smoothly to external change. Variables such as these are a key prerequisite for the generation of welfare in an evolving economy. From a normative point of view, however, this leads us directly back to the problem with which we started: A smoothly working highly dynamic "learning economy" may exhibit great features in itself, but at the same time imply serious hardship for some of the individuals who have to live with it.

\footnotetext{
${ }^{22} \mathrm{cf}$. Bruni and Sugden (2008: 57): "If a market relationship is to be perceived as mutual assistance, the distribution of gains from trade must not deviate too far from whatever standards of fairness are recognized by the parties concerned".
} 
While a similar discrepancy is also relevant in Paretian welfare economics, ${ }^{23}$ the tension between the individualistic and the systemic view on welfare normative issues seems to be particularly troublesome in an evolutionary setting. As Sen (1993) speculates, the temptation to interpret welfare (and "progress" more general) through a systemic lens may be particularly tempting for economists inspired by a Darwinian perspective on the economy. Many evolutionary economists clearly belong to this category. The whole problem is maybe most visible in some of Hayek's later contributions to the policy implications of an evolutionary world-view (Kerstenetzky 2000, 2007). To be sure, Hayek at times conceded that policy should care about the individual well-being (broadly interpreted) of market participants ${ }^{24}$. In his later writings, however, he argued that, given the way processes of institutional evolution work, it would be meaningless to ask whether the individuals affected by them would ever agree to the results, since, given the way supra-individual processes of cultural evolution work, "in any case, our desires and wishes are largely irrelevant" (Hayek 1988: 134). ${ }^{25}$ Hence, welfare came to be detached from the level of individual benefits. Above all, Hayek cared about maintaining certain systemic qualities of the decentralized market system, where knowledge is being processed in such an ingenious way. Whether the individuals liked its impact on their personal well-being or not, these features had to be protected against any attempt to push centralization too far.

On a more applied level, Potts (2004) has recently stressed the importance of the systemic view on welfare in the context of a normative analysis of financial "bubbles". Starting from the premise that bubbles are "natural features of an economic system, and natural mechanisms of economic growth and evolution", he argues that they are "ultimately a sign of system health and vigour, not of decadence and decay" (ibid.: 16), and that policy should appreciate their beneficial effects: "Inside a bubble, the cost of experimentation, and therefore variety generation, is lowered and,... the process of structural change is accelerated... Learning is accelerated within a bubble, and radically

\footnotetext{
${ }^{23}$ Albeit in a much simpler way: Even if the system as a whole reaches a point on the Pareto frontier, this does not imply that all individual members of the system find themselves in a "desirable" state. It only means that the system has exhausted all available gains from voluntary exchange. It does not imply anything about individually realized levels of welfare. Welfare Economics has reacted by complementing its toolbox with criteria such as "potential" Pareto efficiency or social welfare functionals, but these criteria have created conceptual and theoretical problems of their own.

${ }^{24}$ see, for instance, Hayek (1973: 65).

${ }^{25}$ on this, see also Vanberg (1994: 183), Gordon (1981).
} 
new business ideas can get a start, as can radically new products" (ibid.: 18-19). His policy implications are straightforward: "Policy should not worry about bubbles; if anything, and where it is safe to do so, it should perhaps even encourage them." (ibid.: 20).

In light of recent events in global financial markets, this may sound absurd. Potts however has a point in stressing the systemic aspect of welfare: In order to establish the conditions necessary for an evolving economy to work smoothly, bubbles do have some functional properties. The argument gets into trouble, though, as soon as the normative and the instrumental level are mixed: Fast learning and variety generation would then be judged as desirable goals per se. Potts seems to be dimly aware of this risk of producing counter-intuitive policy advice (note his caveat: "where it is safe to do so"), but does not elaborate on this issue.

Welfare can either consist directly in what individuals value or desire (Vanberg 1994; Kerstenetzky 2007) or it can consist in the smooth working of the economic system itself. From an individualistic point of view, the features conducive to a smoothly working system would rather be classified as instrumental variables that would have to be judged according to their contribution to individual well-being. In this sense, we suggest to follow Boulding (1981: 195) who emphasized the point that "from the human point of view, progress is improvement in the state of persons. Everything else is an intermediate good."

\section{Concluding Remarks}

As Nelson and Winter (1982: ch. 15) predict, an evolutionary approach to welfare will necessarily lack the uniform consistency of Paretian welfare economics. In particular, it will not serve to derive strictly provable theorems involving "optimal equilibria", but rather help to engage in comparative institutional analysis on the basis of a multi-faceted (and probably multi-dimensional) notion of welfare. As Metcalfe (2001: 565) puts it, "one important consequence of the Darwinian theory was to banish the idea of perfection from the discussion of progress". But even in its presently still quite abstract form, the evolutionary perspective on the normative issues raised by novelty has already important implications for several conceptual, but also practical policy-related questions. 
As the present paper has argued, Evolutionary Economics currently lacks but needs an approach to welfare that is compatible with its overall outlook on the economy and economic behavior. At the same time, it also possesses the key tools to construct such an approach, in particular by enriching the standard contractarian toolbox of Constitutional Economics with empirical insights into the factors determining human preferences. Finally, we have identified a tension between a strictly individualistic and a systemic interpretation of economic welfare which will certainly make for an interesting challenge for any future contributions to evolutionary welfare economics.

\section{References}

Atkinson, A.B. (2001), The Strange Disappearance of Welfare Economics, Kyklos 54, 193-206.

Audretsch, D.B., Grillo, I. and A.R. Thurik (2007), Explaining entrepreneusrhip and the role of policy: a framework. In: Handbook of research in entrepreneurship policy. Cheltenham: E.Elgar, pp. 1-17.

Binder, M. (2008), Elements of an Evolutionary Theory of Welfare. PhD dissertation, Friedrich Schiller University, Jena, Germany.

Boeri, T., Börsch-Supan, A. and G. Tabellini (2001), Would you like to shrink the Welfare State? A Survey of European Citizens, Economic Policy 16, 9-50.

Boulding, K.E. (1981), Evolutionary Economics. Beverly Hills: Sage.

Broome, J. (2000), Why economics needs ethical theory, mimeo.

Bruni, L. and Sugden, R. (2008), Fraternity: Why the market need not be a morally free zone, Economics and Philosophy 24, 35-64.

Buchanan, J.M. (1977), Freedom in Constitutional Contract. College Station: Texas A\&M University Press.

Buchanan, J.M. (2005), Afraid to be free: Dependency as Desideratum, Public Choice 124, 19-31.

Cordes, C. and C. Schubert (2007), Towards a naturalistic foundation of the social contract, Constitutional Political Economy 18, 35-62.

Dolfsma, W. (2005), Towards a dynamic (Schumpeterian) welfare economics, Research Policy 34, 69-82.

Elster, J. (1982), Sour grapes - utilitarianism and the genesis of wants, in: A.K. Sen and B. Williams (eds.), Utilitarianism and Beyond. Cambridge: Cambridge University Press, pp. 219-238.

Foss, N.J. (2006), Evolutionary Economics and Economic Policy, http://organizationsandmarkets.com/2006/08/02/evolutionary-economics-andeconomic-policy/

Frey, B.S. and A. Stutzer (2007), What Happiness Research can tell us about Self-Control Problems and Utility Mispredictions. In: Frey, B.S. and A. Stutzer (eds), Economics and Psychology: A Promising New Cross-Disciplinary Field. Cambridge MA: MIT Press, pp. 169-195. 
Gordon, S. (1981), The political economy of F.A. Hayek, Canadian Journal of Economics 14, 470-487.

Güth, W. and Kliemt, H. (2008), What Ethics Can Learn From Experimental Economics - If Anything, Jena Economic Research Paper \# 2008-062.

Hayek, F.A. (1945), The Use of Knowledge in Society, American Economic Review 35, 519-530.

Hayek, F.A. (1948), Individualism and Economic Order. Chicago: University of Chicago Press.

Hayek, F.A. (1973), Law, Legislation and Liberty, Vol. I. London: Routledge.

Hayek, F.A. (1988), The Fatal Conceit. Chicago: University of Chicago Press.

Hodgson, G.M. (1999), Economics and Utopia: Why the Learning Economy is not the End of History. London: Routledge.

Kahneman, D., Wakker, P.P. and R. Sarin (1997), Back to Bentham? Explorations of experienced utility, Quarterly Journal of Economics 112, 375-405.

Kerstenetzky, C.L. (2000), Hayek: The Evolutionary and the Evolutionist, Rationality and Society 12, 163-184.

Kerstenetzky, C.L. (2007), Hayek and Popper on ignorance and intervention, Journal of Institutional Economics3, 33-53.

Keynes, J.N. (1917), The Scope and Method of Political Economy. London: Macmillan.

Lessig, L. (1995), The Regulation of Social Meaning, University of Chicago Law Review 62, 943-1045.

Metcalfe, J.S. (2001), Institutions and Progress, Industrial and Corporate Change 10, 561-586.

Metcalfe, J.S. (2005), Systems failure and the case for innovation policy. In: Llerena, P. and M. Matt (eds.), Innovation Policy in a Knowledge-Based Economy. Berlin: Springer, pp. 47-74.

Nelson, R.R. (1981), Assessing private enterprise: an exegesis of tangled doctrine, Bell Journal of Economics 12, 93-111

Nelson, R.R. (1990), Capitalism as an engine of growth, Research Policy 19, 193-214.

Nelson, R.R. (1995), Recent Evolutionary Theorizing about Economic Change, Journal of Economic Literature 33, 48-90.

Nelson, R.R. and Winter, S.G. (1982), An Evolutionary Theory of Economic Change, Cambridge MA: Belknap Press

Ng, Y.-K. (2003), From preference to happiness: Towards a more complete welfare economics, Social Choice and Welfare 20, 307-350.

North, D.C. (1990), Institutions, Institutional Change and Economic Performance. Cambridge: Cambridge University Press.

Pelikan. P. (2002), Why economic policies need comprehensive evolutionary analysis. In: Pelikan, P. and G. Wegner (eds.), Evolutionary Thinking on Economic Policy. Cheltenham: E. Elgar, pp. 15-45.

Penz, G.P. (1986), Consumer Sovereignty and Human Interests. Cambridge: Cambridge University Press.

Potts, J. (2004), Liberty Bubbles, Policy 20, 15-21.

Robbins, L. (1935), An Essay on the Nature and Significance of Economic Science. London: Macmillan.

Scanlon, T.M. (1991), The moral basis of interpersonal comparisons. In: Elster, J. and Roemer (eds.), Interpersonal Comparisons of Well-Being. Cambridge MA:

Cambridge University Press, pp. 17-44. 
Schumpeter, J.A. (1912), Theorie der wirtschaftlichen Entwicklung. Berlin: Duncker \& Humblot.

Schumpeter, J.A. (1942), Capitalism, Socialism and Democracy. London: Allen \& Unwin.

Sen, A.K. (1977), On Weights and Measures: Informational Constraints in Social Welfare Analysis, Econometrica 45, 1539-1572.

Sen, A.K. (1993), On the Darwinian View of Progress, Population and Development Review 19, 123-137.

Sen, A.K. (1996), On the Foundations of Welfare Economics: Utility, Capability, and Practical Reason. In: Farina, F., Hahn, F. and S. Vanucci (eds), Ethics, Rationality, and Economic Behavior. Oxford: Clarendon, pp. 50-65.

Sugden, R. (1993), Welfare, Resources and Inequality, Journal of Economic Literature 31, 1947-1963.

Sugden, R. (2004), The opportunity criterion: Consumer sovereignty without the assumption of coherent preferences, American Economic Review 94, 1014-1033.

Sugden, R. (2007), The value of opportunities over time when preferences are unstable, Social Choice and Welfare 29, 665-682.

Sugden, R. (2008), Why incoherent preferences do not justify paternalism, Constitutional Political Economy 19, 226-248.

Sunstein, C., and R. Thaler (2003a), Libertarian paternalism, American Economic Review, Papers \& Proceedings 93, 175-179.

Sunstein, C., and R. Thaler (2003b), Libertarian paternalism is not an oxymoron, University of Chicago Law Review 70, 1159-1202.

Vanberg, V.J. (1994), Cultural Evolution, Collective Learning, and Constitutional Design. In: Reisman, D. (ed.), Economic Thought and Political Theory. Boston: Kluwer, pp. 171-204.

Vanberg, V.J. (2006), Human intentionality and design in cultural evolution. In: Schubert, C. and G. v.Wangenheim (eds.), Evolution and Design of Institutions. London: Routledge, pp. 197-212.

Vis, B. and K. van Kersbergen (2007), Why and how do political actors pursue risky reforms? Journal of Theoretical Politics 19, 153-172.

Wegner, G. (1997), Economic policy from an evolutionary perspective - a new approach. Journal of Institutional and Theoretical Economics 153, 485-509.

Wegner, G. (2008), Substantive versus Procedural Liberalism - Exploring a Dilemma of Contemporary Liberal Thought, Journal of Institutional and Theoretical Economics, forthcoming.

Weizsäcker, C.C. (1971), Notes on Endogenous Change of Tastes, Journal of Economic Theory 3, 345-371.

Weizsäcker, C.C. (2005), The Welfare Economics of Adaptive Preferences, Preprint, Max Planck Institute for Research on Collective Goods, \# 05/11.

Witt, U. (1991), Economics, Sociobiology, and Behavioral Psychology on Preferences, Journal of Economic Psychology 12, 557-573.

Witt, U. (1992), The endogenous Public Choice theorist, Public Choice 73, 117-129.

Witt, U. (1996), Innovations, Externalities and the Problem of Economic Progress, Public Choice 89, 113-130.

Witt, U. (2001), Learning to Consume - a theory of wants and the growth of demand, Journal of Evolutionary Economics 11, 23-36. 
Witt, U. (2003), Economic Policy Making in Evolutionary Perspective, Journal of Evolutionary Economics 13, 77-94.

Witt, U. (2004), Beharrung und Wandel - ist wirtschaftliche Evolution theoriefähig? Erwägen - Wissen - Ethik 15, 33-45.

Witt, U. (2008), What is specific about Evolutionary Economics? Journal of Evolutionary Economics, forthcoming.

Witt, U. and Schubert, C. (2008), Constitutional interests in the face of innovations: how much do we need to know about risk preferences? Constitutional Political Economy $19,203-225$. 